Committee had been discontinued. He saw an urgent need for consultation between those who had given papers in deciding on the dietary standards which were necessary for adequate nutrition of the human subject. It was equally essential to discriminate between the rival claims of the various farm animals to share in such foodstuffs as were available.

\section{LUNG ABSCESS}

At a meeting of the Manchester Medical Society on Oct. 1 Mr. W. F. Nicholson, reading a paper on this subject, said that bronchial obstruction with secondary infection was the common cause of lung abscess. In normal health the cilia lining the bronchial tree kept the air passages free from organisms and debris. When ciliary action was impaired by trauma, infection, or growth, coughing was effective in preventing bronchial obstruction. When coughing was embarrassed by pain or anaesthesia or tenacious secretion, bronchial obstruction might occur.

An abscess due to bronchial embolism was peripheral in the lung, though it might not present on the costal surface. Because the subapical segment of the upper lobe and the apical segment of the lower lobe contained the most dependent bronchi in the lateral and supine positions respectively, these segments were most frequently affected, and consequently most inhalation abscesses presented on the costal surface of the lung corresponding to these segments. The upper-lobe abscess was common after operations on the upper réspiratory tract, in which a lateral position was usually employed in the immediate postoperative period. Lower-lobe abscess was often due to abdominal operations, which were associated with a supine or Fowler's position. A putrid lung abscess was frequently undiagnosed because it was still not widely known that such an abscess could exist without foul sputum. When the abscess ruptured into the bronchial tree sputum would be present; but even before this happened there might be fetid breath.

Treatment was by drainage, either bronchial (postural) or external (by operation). In either case location of the lesion must be exact if treatment was to be rational. The responsibility of the physician in these cases was heavy. If he delayed external drainage, in many cases the disease spread to a diffuse suppurative pneumonia of a lobe, which would eventually require a lobectomy. Moreover, the immediate mortality of conservative treatment was considerable. Only by sharing the responsibility with a surgeon from the beginning could drainage be instituted promptly in cases which did not respond to medical measures. Chemotherapy and antibiotics were of value, but did not replace drainage. Bronchoscopy was of value in locating the broncho-pulmonary segment of the abscess, in improving bronchial drainage, and in excluding a foreign body or growth; as a curative measure it was of little more value than postural drainage. Surgical drainage would decrease mortality and morbidity.

At a meeting of the Liverpool Medical Institution on Oct. 23, with the president, Dr. H. Wallace-Jones, in the chair, Dr. R. Lipman read a case history illustrating psychogenic factors in dysmenorrhoea, menorrhagia, and Mittelschmerz. Mr. Barry McMurray reviewed the various lesions which may occur in sprained ankles.

The autumn number of Biology and Human Affairs (obtainable from the British Social Hygiene Council, Tavistock House North, Tavistock Square, London, W.C.1, 2s. 6d.) contains an interesting article by Prof. J. M. Mackintosh on "The Contribution of Science to Comfort in the Home." He comments on the delay between the discovery of knowledge and its application in the home-a popular topic of conversation among housewives after reading articles on the contributions that science could make to their comfort. $\mathrm{He}$ attributes it partly to the conservatism of builders, and to those people, often elderly, who choose designs for new houses for working people- "the cold, dead hand of a passing age presses too hard on an age that is coming to birth."

\section{Correspondence}

\section{Anaesthesia for Head and Neck Surgery}

SiR,-The article by Dr. J. G. Bourne (Oct. 25, p. 654) on the subject of thiopentone-nitrous-oxide-oxygen anaesthesia with curare for head and neck surgery will have been read with interest by all. May I trespass on your columns to say that my reaction was one of admiration for the obvious skill of the author? Following hard on this, however, I found myself asking, does this method in fact promote the well-being of the patient and constitute an advance in the degree of safety afforded to him, or does it rather represent an advance in the technical skill of the author? (For these two virtues, though usually so, are not invariably synonymous.) My doubts were increased when I saw that, in the five instances in which the advantages of the new method or the objections to the old were enumerated, on every occasion the time factor was given pride of place. The factors such as the degree of safety and the comfort or discomfort of the patient followed in (presumably) their due order. One cannot but gain the impression that the speed of the method constitutes its chief attraction in the author's estimate.

I also find it rather hard to agree with the statement that for procuring the initial relaxation for intubation there is no agent as safe as curare. I have yet to see the figures that will convince me that the dangers of a few ounces of ether are greater than those of $20 \mathrm{mg}$. of curare. The amount of ether required for a blind intubation (and in the majority of head and neck cases a nasal tube is as good as an oral) is not very large. If the head is not moved, anaesthesia can be maintained with a minimum trickle ; and if it is possible to turn off the ether 10-15 minutes before the end, then the degree of post-operative nausea is but reasonably transient in most cases. That the degree of relaxation afforded by this method should be cited as one of its virtues caused me a mild degree of surprise, for I have worked with Continental as well as English surgeons (through circumstance rather than choice), and have never been asked, during a headand-neck operation, for a degree of relaxation that would necessitate the giving of $20 \mathrm{mg}$. of curare.

Surely one of the advantages of curare is that it provides where needed a degree of relaxation that could otherwise only be brought about by some form of nerve block or the use of toxic amounts of the inhalational agents. Is, then, the method described by the author a logical outcome of this; or is it a very skilled demonstration of cracking a medium-sized walnut with an out-size sledge-hammer ?-I am, etc.,

London, W.8.

G. C. Steel.

SIR,-I read with interest Dr. J. G. Bourne's article (Oct. 25, p. 654), and my purpose in commenting is to inquire rather than to criticize. Under "Method" the sequence enumerated appears to me to be capable of improvement both in the safety factor and in time. Would it not be better to adopt the technique for curare advised by Dr. Gray, of Liverpool, and to give the injections in the following order? (1) Test injection of " tubarine," $5 \mathrm{mg}$. (one-third average induction dose); (2) wait for four minutes to observe its effect, from which to judge the total injection dosage advisable, and then inject this-say, a further $10 \mathrm{mg}$.; (3) immediately give in a separate vein an intravenous barbiturate in adequate dosage.

By this time the patient will be ready for laryngoscopy, "cocainization," and intubation. Then $\mathrm{N}_{2} \mathrm{O}-\mathrm{O}_{2}$ may be continued, with a further relay of barbiturate if necessary at a later stage. By this there is not only a safer control of curare but also a saving of time, as the effect of both the tubarine and barbiturate synchronize.-I am, etc.,

Barton-on-Sea, Hants.

Harold C. J. Ball.

\section{All the Vitamins}

SIR,-When you published Dr. Leslie J. Harris's article (Nov. 1, p. 681) in reply to a simply worded request in "Any Questions?" one expected a simple reply, giving the answer in words which the average doctor could understand. I wonder if the reader who sent that question is satisfied by Dr. Harris's 
article. Is he interested to know that $a$ and $\beta$ carotene, kryptoxanthine, lepronene, echinenone, and myxoxanthine, etc., serve as provitamins for vitamin A ? Does he find it easy to learn the eye changes of $A$ deficiency when he reads that xerotic changes, Bitot's'spots, xerophthalmia, and keratomalacia occur, or would he prefer to have a description of the appearance of the eye in less technical terms such as dry or scaly? Similarly with nicotinamide. Does it convey anything to the average reader to learn that it is a component of codehydrogenase I or "Euler's cozymase" diphosphopyridine nucleotide, and also of codehydrogenase II or Warburg's enzyme triphosphopyridine nucleotide? If the space taken by those words had described what the mental changes of pellagra are (we are told there are mental changes, but whether mania, depression, dementia, or hallucinations is not stated), would that have been more helpful ?

No doubt the article is fuli of accurate and scholarly information to the advanced biochemist and nutritional research worker, but such persons have their special books on the subject and do not need to read it in the B.M.J. Surely your job as editor is to see that information and fact rather than incomprehensible words are dispensed to your readers. There is no mention of the fact that the teeth become loose and fall out in scurvy (though we are told the reversibly oxidized derivative dehydroascorbic acid is active in treating it), and nothing is said of the occurrence of the signs of riboflavin deficiency in the common iron-deficiency anaemia of women, though the occurrence of riboflavin as iso-alloxazine-adenine-dinucleotice is mentioned. One could go on indefinitely. Under vitamin D we do not learn whether it helps children to grow better teeth or not, but are enlightened about vitamin $D_{3}$ being irradiated 7-dehydrocholesterol (cholestadien-3-ol).

I am not criticizing the article itself, only your policy in printing it. If $\mathrm{I}$ am wrong in believing that less than $2 \%$ of your readers understand most of the technical terms, I apologize for unfair criticism, but if I am right, I suggest that you owe it to your subscribers to give them useful, understandable, and practical knowledge instead of allotov-words-2-obscure-4-any 1 2 succidin-understanding them.-I am, etc.,

London, N.W.10.

RichaRd Asher.

${ }^{* *}$ The question asked was as follows: Q.-Please give a list of vitamins with all their different names and with notes on the signs and symptoms of deficiency [our italics]. It was assumed that medical men know the meaning of medical technical words such as xeropththalmia.-ED., B.M.J.

Sir,- Those who have to keep pace with the literature on vitamins will best appreciate Dr. Leslie J. Harris's difficulty in attempting to compress even into three pages of the Journal ${ }^{1}$ the answer to the question about vitamins which a correspondent expected to appear as a brief reply in "Any Questions?" There are nevertheless one or two points in Dr. Harris's article which should, I feel, be slightly amplified. For example, Dr. Harris includes para-aminobenzoic acid ("paba") in his least significant group-viz.. those vitamins needed by animals but whose significance for humans is uncertain. It has, however, been shown in several series of clinical trials ${ }^{2-4}$ that paba in pharmacological dosage has a pronounced effect in the treatment of the rickettsial infections in man. The vitamin is listed in Appendix $B$ in an M.R.C. report ${ }^{5}$ among substances showing no activity in a 20-mg. dose given to a 15-g. mouse, but no human test on it is recorded in the report.

A further point which often arises occurs in connexion with the value of vitamin $\mathrm{E}$ in human abortion. As long ago as 1940 Bacharach demonstrated mathematically ${ }^{6}$ that the probability of the results obtained with it in the treatment of a series of 42 patients, who had had four or more abortions, having been obtained by chance was one in $10^{10}$, a degree of probability excelled or equalled by very few clinical trials indeed. In connexion with the value of certain members of the $B_{2}$ complex for the human, there appears to be a slight inconsistency between the editorial advice ${ }^{7}$ to take " supplements ... of yeast or wheat-germ preparations ... rather than preparations of isolated vitamins" (on the grounds that it is implied by $M$. Richards's work ${ }^{8}$ that "ingestion of large amounts of one member of the B group ... may induce signs of deficiency of . other members") and Dr. Harris's relegation of pyridoxin to this third (i.e., least significant) group, since Richards's work was concerned particulariy with pyridoxin deficiency. Subject to a further point to which I refer below, one cannot but agree with the editorial recommendation, but it is a fact that Richards's work was concerned with induced pyridoxin lack. If we accept the transference to man of the implications of Richards's work as in your leading article, we can no longer logically regard pyridoxin as of doubtful physiologicai significance in nutrition.

My reservation in connexion with your editorial advice relates to the recommendation of "yeast ... preparations," and is twofold. First, the comparatively large amount of yeast which a patient must consume is not generally appreciated. While there are, of course, some highly potent strains, at least an ounce of a normal yeast must be eaten to provide even a prophylactic dose of vitamin $\mathbf{B}_{1}$. Having regard to the flavour of yeast, this is rarely practicable-least of all, as a rule, for those whose need is greatest. Secondly, it is essential that every precaution should be taken by the maker or the user to destroy all viable cells in the yeast. It has been shown repeatedly $\mathrm{y}^{914}$ that yeasts cannot all be relied upon as sources of vitamin $B_{1}$ and that yeasts may be used in the human as negative sources of the vitamin. Indeed certain yeasts are actually recommended by Kingsley and Parsons ${ }^{12}$ as offering a convenient and rapid means of depleting human subjects of $B_{1}$ without the need of using unpalatable "deficient" diets. This fact has been widely overlooked, and both in this country and in the U.S.A. the "liveness" of certain yeasts has actually been adduced as a recommendation for their use.

In conclusion I should like to refer to two questions of dosage or standard requirements. It is now becoming clear (and Dr. Harris, in citing the L. of $N$. standard for vitamin $\mathrm{A}-3,000$ i.u. as carotene, equivalent to 1,000 to 1,500 i.u. as preformed "animal" A-gives tacit approval to this viewpoint) that the human requirement is nowhere near the figure of 4,000 i.u. included in such prophylactic preparations as vitamin $\mathrm{A}$ and $\mathrm{D}$ capsules, N.W.F., still less the 4,500 i.u. included in " pluravit," N.W.F.

It does appear, therefore, that in the present state of world shortage of vitamin A more general acceptance of the lower figures-fairly conclusively established since the L. of $\mathrm{N}$. standards were evolved, by the Accessory Food Factors Committee of the M.R.C. ${ }^{15}$ - could result both in substantial financial economies in this country without the slightest risk of prejudice to health and, what is much more important, in the freeing of material for those in need who cannot at present be supplied.

$\mathrm{My} \cdot$ other point is in the reverse direction. Dr. Harris suggests (and few nutritionists would disagree) a daily prophylactic requirement of 1-2 mg. riboflavin. Why, then, does the formula for pluravit, N.W.F., provide only $0.05 \mathrm{mg} . ?-\mathrm{a}$ quantity which is so inadequate in relation to needs that a food manufacturer claiming riboflavin activity on the label of a foodstuff providing in normal daily usage even as much as four times the pluravit-content figure would still contravene the Ministry of Food's directive relating to the administration of the Labelling of 'Foods Order, and would also render himself liable to prosecution under the relevant Defence Regulation for misleading the purchaser.

These various points relating to requirements of vitamin A, therapeutic usefulness of para-aminobenzoic acid and vitamin $E$, precautions in the choice of yeast preparations, and the token riboflavin content of pluravit are all worthy of note by those prescribing vitamin preparations.-I am, etc.,

The Research Laboratories, Vitamins Ltd.,
London, W.6.

M. D. Wright.

REFERENCES

1 British Medical Journal, 1947, 2, 681.
2 Tierney, J. Amer. med. Ass., 1946, 131, 280.
3 Yeomans et al., ibid., 1944, 126, 349.
4 Flinn et al., ibid., 1946, 132, 911.
5 Med. Res. Cncl. Sp. Rep. 255, 1946.
6 British Medical Journal, 1940, 1, 890.
7 Ibid., 1947, 2, 696.
8 Ibid., 1945, 1, 433.
9 Walker and Nelson, Amer. J. Physiol., 1933, 103, 25.
10 J. Amer. med. Ass., 1946, 132, 582.
11 Van Loesecke, ibid., 1946, 22, 485.
12 Kingsley and Parrons, J. Nutrit., 1947, 34, 321.
13 Hochberg et al., ibid., 1945, 30, 201.
14 Parsons and Collord, J. Amer. Diabetic Ass., 1942, 18, 805.
15 Med. Res. Cncl., 1945, Nature, 156, 11.

Vitamin-C Content of Fruit-squash Concentrates

SiR,-Your question and answer on this subject in "Any Questions?" (Aug. 23, p. 318) has come to our notice. In our view both the question and the answer are couched in terms which may give rise to some misconception regarding the true position. It is an accepted fact that fruit squashes made from citrus fruits retain no appreciable quantities of ascorbic acid, 